\title{
Platelet Interaction with Polymerizing Fibrin
}

\author{
Stefan Niewiarowski, Erwin Regoeczi, Gwendolyn J. Stewart, \\ Andrew F. Senyi, and J. Fraser Mustard \\ From the Department of Pathology, McMaster University, \\ Hamilton, Ontario, Canada
}

\begin{abstract}
A в S TRAC T Interaction of washed pig, rabbit, or human platelets with fibrinogen was studied during its transition to fibrin using photometric, isotopic, and electron microscopic techniques. Untreated fibrinogen and fully polymerized fibrin had no detectable effect on platelets. Fibrinogen, incubated with low concentrations of reptilase or thrombin, formed intermediate products which readily became associated with platelets and caused their aggregation. Neutralization of the thrombin did not prevent this interaction. In the absence of fibrinogen, reptilase did not affect platelets.

The interaction of polymerizing fibrin with platelets was accompanied by small losses of platelet constituents (serotonin, adenine nucleotides, platelet factor 4 , and lactic dehydrogenase). This loss did not appear to be the result of the platelet release reaction. Inhibitors of the release reaction or of adenosine diphosphate (ADP)induced aggregation did not prevent the interaction of platelets with polymerizing fibrin. Apyrase or prostaglandin $\mathrm{E}_{1}\left(\mathrm{PGE}_{1}\right)$ reduced the extent of platelet aggregation by polymerizing fibrin, but the amount of protein associated with platelets was slightly increased.

The interaction of polymerizing fibrin with platelets
\end{abstract} was completely inhibited by ethylenediaminetetraacetate (EDTA) or ethylene glycol bis $(\beta$-aminoethyl ether) $\mathrm{N}$, $\mathrm{N}, \mathrm{N}^{\prime}, \mathrm{N}^{\prime}$-tetraacetic acid (EGTA).

Fibers formed in solutions of polymerizing fibrin were larger in the presence than in the absence of washed platelets, suggesting that platelets affect fibrin polymerization. The adherence of platelets to polymerizing fibrin may be responsible for the establishment of links between platelets and fibrin in hemostatic plugs and thrombi.

Dr. Stewart's present address is the Specialized Center for Thrombosis Research, Temple University, Department of Medicine, Philadelphia, Pa.

Received for publication 19 August 1971 and in revised form 15 October 1971.

\section{INTRODUCTION}

Although platelets and fibrin are regarded as the two essential components of the hemostatic plug, their interaction is not well understood. Platelets do not readily adhere to fully polymerized fibrin in which traces of thrombin have been neutralized (1). Apitz (2) found that "profibrin," an intermediate product of the transition to fibrin, aggregated platelets in oxalated plateletrich plasma. Solum (3) observed aggregation of platelets in heated platelet-poor plasma in the presence of polymerizing fibrin monomers; during the reaction ADP was released from the platelets. We found recently that induction of partial polymerization of fibrin, by minute amounts of thrombin resulted in aggregation of platelets in platelet-rich plasma (4).

All this points to the possibility that intermediate products of the fibrinogen-fibrin conversion possess an affinity to platelets which is appreciably higher than that of fully polymerized fibrin, but the difficulty in establishing this is that fibrin can be maintained in the monomeric state only by the use of cytotoxic concentrations of solvents such as urea or sodium bromide. Washed platelets in suspension can be exposed to solutions of polymerizing fibrin, in which fibrin monomers are continuously generated in small quantities and allowed to form intermediate polymers without becoming insoluble. We have studied the adherence of polymerizing fibrin to platelets and its effect on platelet aggregation and the release of platelet constituents.

\section{METHODS}

Fibrinogen. Human and bovine fibrinogens, prepared by the method of Blombäck and Blombäck (5) were obtained commercially. ${ }^{1}$ The lyophilized powders, containing about $50 \%$ salt by weight, were reconstituted with distilled $\mathrm{H}_{2} \mathrm{O}$ to yield a $1 \%$ solution of protein and the $\mathrm{pH}$ was adjusted to 7.3-7.4 with $0.1 \mathrm{~N} \mathrm{NaOH}$. Pig fibrinogen was prepared by fractionation with ammonium sulphate (6). The clottability of the various preparations, as estimated by an isotopic

${ }^{1}$ Kabi, Stockholm, Sweden. 
technique (7), ranged between 90 and $95 \%$. If not further specified, "fibrinogen" will denote the human protein.

Clotting enzymes. Thrombin, reptilase, ${ }^{3}$ and ancrod "were dissolved and/or diluted to the desired concentration using $0.9 \% \mathrm{NaCl}$.

Polymerizing fibrin. $0.45 \mathrm{ml}$ fibrinogen was incubated with $0.05 \mathrm{ml}$ of $0.3 \%$ reptilase, or $0.05 \mathrm{ml}$ thrombin solution containing $0.2-1.0 \mathrm{U} / \mathrm{ml}$ or $0.05 \mathrm{ml}$ ancrod $(0.1 \mathrm{U} / \mathrm{ml})$ in a water bath at $37^{\circ} \mathrm{C}$. Incubation with thrombin was in siliconized tubes. Under these circumstances, the first visible fibrin strands appeared after 17-22 min of incubating fibrinogen with reptilase. A firm clot was formed within $30 \mathrm{~min}$. The time of fibrin formation with thrombin was more variable, possibly because of the known instability of this enzyme in dilute solutions. Ancrod, at a final concentration of 0.01 $\mathrm{U} / \mathrm{ml}$, clotted $1 \mathrm{ml}$ of a $1 \%$ solution of fibrinogen in about $10 \mathrm{~min}$.

Sonicated clot. Fibrinogen was incubated with reptilase for $60 \mathrm{~min}$ and the synerezed fibrin was sonicated ${ }^{5}$ in $10 \mathrm{ml}$ Tyrode-albumin solution for $5 \mathrm{~min}$

Reagents. Hirudin, ${ }^{6}$ heparin, ${ }^{7}$ and apyrase ${ }^{6}$ were made up in $0.9 \% \mathrm{NaCl}$. EDTA-Ną and EGTA- $\mathrm{Na}_{2}{ }^{8}$ were dissolved in $0.85 \% \mathrm{NaCl}, \mathrm{PGE}_{1}{ }^{\circ}$ was first made up to a $1 \%$ solution in $95 \%$ ethanol and then diluted using $0.2 \% \mathrm{Na}_{2} \mathrm{CO}_{8}$ in $0.9 \%$ $\mathrm{NaCl}$ to a final concentration of $1 \mathrm{mg} / \mathrm{ml}\left(=2.9 \times 10^{-8} \mathrm{M}\right)$. Diisopropylfluorophosphate ${ }^{10}$ (DFP) ${ }^{11}$ was dissolved in isopropyl alcohol to give a $1 \mathrm{~m}$ solution, from which a $0.1 \mathrm{M}$ solution was prepared with $0.12 \mathrm{M} \mathrm{Na}_{2} \mathrm{CO}_{3}$. Further dilutions were done with distilled $\mathrm{H}_{2} \mathrm{O}$ and the $\mathrm{pH}$ was adjusted to 7.4

Isolation of platelets. Washed pig, rabbit, and human platelets were prepared according to previously published methods $(8,9)$. After two washings, they were resuspended in Tyrode-albumin solution containing apyrase $(10 \mu \mathrm{g} / \mathrm{ml})$ which has been shown to stabilize platelet suspensions (10). The washing and suspending fluids used for the preparation of pig platelets were of a higher osmolarity than those used to prepare rabbit and human platelets, the difference amounting to an extra $50 \mathrm{mg} \mathrm{KCl}$ and $90 \mathrm{mg} \mathrm{NaCl} / 100 \mathrm{ml}$. Finally, platelet counts were adjusted to $10^{\circ} / \mathrm{mm}^{8}$. Unlike human and pig platelets, rabbit platelets did not require the addition of fibrinogen to be sensitive to low concentrations of ADP.

Exposure of platelets to polymerizing fibrin. Unless otherwise stated, $0.4 \mathrm{ml}$ of a solution of polymerizing fibrin was rapidly mixed with $1 \mathrm{ml}$ platelet suspension ( $10^{\circ}$ cells) in the cuvette of a Payton aggregometer ${ }^{12}$ and the light trans-

'Parke, Davis \& Co., Detroit, Mich.

${ }^{3}$ Reptilase, a gift by Pentapharm, Basle, Switzerland. Batches 428, 439-441, and 464 which were free of the agent causing platelet aggregation were used.

-Arvin, Twyford Laboratories, London, England.

Sonifier cell disruptor, Ultrasonic Systems, Farmingdale, N. Y.

- Apyrase batch 89 B-5100, Sigma Chemical Co., St. Louis, Mo.

${ }^{7}$ Connaught Medical Research Laboratories, Toronto, Ontario, Canada.

${ }^{8} \mathrm{~K} \& \mathrm{~K}$ Labs Inc., Plainview, N. Y.

- Supplied by The Upjohn Co., Kalamazoo, Mich.

${ }^{10}$ General Biochemicals, Chagrin Falls, Ohio.

11 Abbreviations used in this paper: AN, adenine nucleotide; DFP, diisopropylfluorophosphate; EGTA, ethylene glycol bis ( $\beta$-aminoethyl ether) $\mathrm{N}, \mathrm{N}, \mathrm{N}^{\prime}, \mathrm{N}^{\prime}$-tetraacetic acid $5-\mathrm{HT}-{ }^{8} \mathrm{H}$, serotonin- ${ }^{8} \mathrm{H}$; LDH, lactic dehydrogenase; $\mathrm{PF}_{4}$ platelet factor $4 ; \bar{X}$, mean.

${ }^{12}$ Payton, Scarborough, Ontario, Canada. mission of the mixture was recorded over a minimum of 3 min. During this time the suspension was continuously stirred at a rate of $1100 \mathrm{rpm}$. Results were expressed in arbitrary units (LTU) which corresponded to the increase in light transmission. The procedure was based on the method of Mustard, Hegardt, Rowsell, and MacMillan (11) for studying platelet aggregation.

Labeling platelets with serotonin- ${ }^{8} H$ (5-hydroxytryptamine, $5-H T)$. The compound ${ }^{23}$ (SA: $5.4 \mathrm{mCi} / \mathrm{mg}$ ) was dissolved in $0.85 \% \mathrm{NaCl}$ and added to the first washing fluid $(0.3$ $\mu \mathrm{Ci} / 10^{\circ}$ cells). After an incubation for $5 \mathrm{~min}$ at room temperature, the platelets were washed and resuspended in Tyrode-albumin solution as already described. Approximately $90 \%$ of the radioactivity was taken up by the platelets.

Measuring the release of radioactivity from platelets labeled with $5-H T-{ }^{8} H$. At the end of the experiment, platelets were immediately centrifuged for $1 \mathrm{~min}$ at $15,000 \mathrm{~g}$ in an Eppendorf centrifuge. ${ }^{14}$ A sample of the supernate $(0.1 \mathrm{ml})$ was added to a mixture of $10 \mathrm{ml}$ liquid scintillation solution $1,{ }^{15} 2 \mathrm{ml} 98 \%$ ethanol, and $0.25 \mathrm{ml}$ NCS solubilizer. ${ }^{13}$ The radioactivity in the supernate was expressed as a percentage of the total radioactivity in $0.1 \mathrm{ml}$ platelet suspension.

Platelet factor $4\left(P F_{4}\right)$. Release of $\mathrm{PF}_{4}$ was assayed as described by Niewiarowski and Thomas (12)

Adenine nucleotides $(A N)$ release. $(13,14)$ The supernates from platelet suspensions were mixed with an equal volume of $6 \%$ perchloric acid and the optical density of the deproteinized media was estimated at $260 \mathrm{~m} \mu$. Readings were converted into nucleotide concentrations by the use of a calibration curve for adenosine (dissolved in platelet-suspending medium and treated with perchloric acid) and results were expressed as percentages of the nucleotide content of the original platelet suspension. It is recognized that this is not a specific assay for adenine nucleotides, and therefore only gives an estimate of the material released.

Lactic dehydrogenase $(L D H)$ assay. This was done using the method of Bergmeyer, Bernt, and Hess (15). Released quantities were expressed as percentages of the total activity in sonicated platelet suspensions.

Studies with fibrinogen-125 I. Fibrinogen was labeled with iodine monochloride (16) at levels of substitution not exceeding one atom of iodine per molecule of protein. Nonradioactive fibrinogen was mixed immediately before each set of experiments with $0.1-0.2 \%$ of labeled protein (v/v). Samples were counted in an automatic gamma spectrometer. ${ }^{15}$

For each assay with polymerizing fibrin two parallel samples were set up, i.e. one containing platelets and one containing platelet suspending fluid but no platelets. After a $3 \mathrm{~min}$ observation period in the aggregometer, both samples were centrifuged in an Eppendorf centrifuge as described above and the supernatant fluid removed. Sediments were dispersed in $0.5 \mathrm{ml} \mathrm{H} \mathrm{H}_{2} \mathrm{O}$ by sonication and the centrifuge tubes were rinsed with an equal volume of $1 \mathrm{~N} \mathrm{NaOH}$. Finally, sonicated pellets and washing fluids were pooled in counting vials. Radioactivity was expressed as a percentage of a duplicate standard. The latter consisted of nonincubated fibrinogen- ${ }^{125} I$ equaling in radioactivity the amount used for the assays.

Most samples were set up in duplicate and some in triplicate. Test and control samples were processed in an identical manner throughout. In the absence of polymerizing fibrin the blank values were low: $1.47 \%$ (SD \pm 0.38 ) with $10^{\circ}$ platelets, and $1.02 \%(\mathrm{SD} \pm 0.22)$ with no platelets.

${ }^{13}$ Amersham/Searle Corp., Arlington Heights, Ill.

${ }^{14}$ Brinkmann Instruments, Rexdale, Ontario, Canada.

${ }^{15}$ Packard Instrument Co., Downers Grove, Ill. 
Electron microscopy. Preparations were fixed in osmium tetroxide and processed for microscopy either by shadow casting (17) or by thin sectioning (18).

Statistical evaluation. Means $(\overline{\mathrm{X}})$, and standard deviations (SD, the square root of variance) were calculated by standard methods. Significance of a difference between two means was calculated by Student's $t$ test, those among several means by Duncan's multiple range test (19).

\section{RESULTS}

Effect of polymerizing fibrin on washed pig, human, or rabbit platelets. The addition of a fibrinogen solution preincubated with a low concentration of reptilase to washed pig platelets caused an increase in light transmission (Fig. 1). Reptilase, or fibrinogen solutions or fibrin clots dispersed by sonication had no effect. The length of time the fibrinogen solution was incubated with the reptilase before it was added to the platelet suspension influenced the speed of the change in light transmission. Fibrinogen solution incubated with ancrod produced a similar effect to that found with the reptilase-fibrinogen mixture. A similar effect was also found with thrombin-fibrinogen mixtures (Fig. 2). Since it was possible that the traces of thrombin present in this mixture could have caused platelet aggregation, DFP was added to the mixture. The inactivation of thrombin by DFP before addition of the incubation mixture to platelet suspension had no effect on the magnitude of change in light transmission (Fig. 2). As can be seen from the experiment presented in Fig. 3, polymerizing fibrin affected in a similar way suspensions of human, rabbit, and pig platelets. Solutions of human, bovine, and pig fibrinogen did not cause platelet aggregation. However, polymerizing fibrin prepared from fibrinogen isolated from each of these three species was equally effective with platelets from all three species.

Electron microscopic examination of the platelet suspension after the addition of the reptilase-fibrin mix-
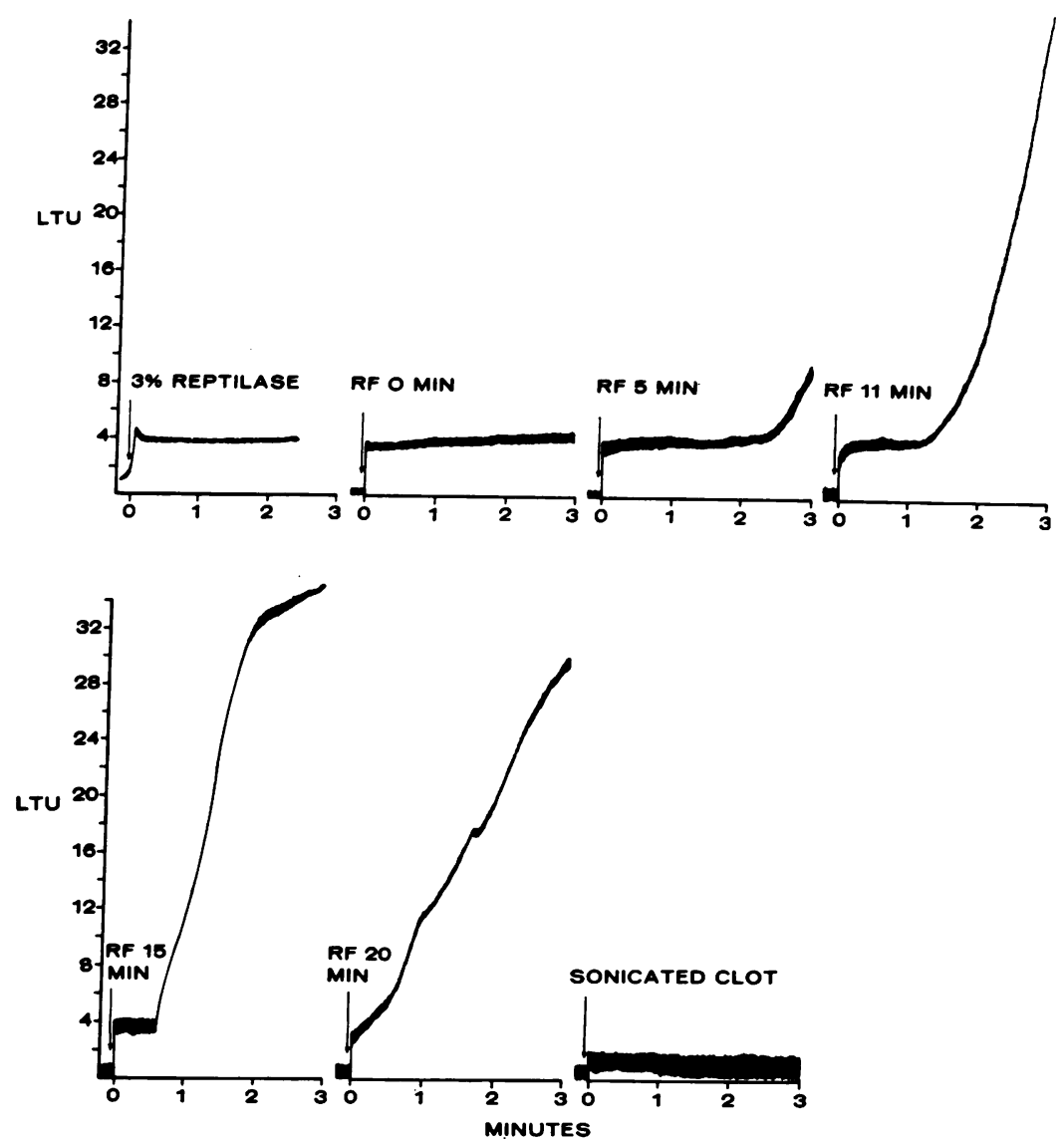

FIGURE 1 Light transmission through suspension of pig platelets $\left(10^{\circ}\right.$ cells/ $\mathrm{mm}^{3}$ ) under various experimental conditions. Tests were carried out at $37^{\circ} \mathrm{C}$ the addition of each test substance is marked by an arrow. These were: $0.1 \mathrm{ml}$ $3 \%$ reptilase; $0.4 \mathrm{ml}$ reptilase fibrin ( $R F$ ) allowed to polymerize for the time intervals indicated in the figure, $0.4 \mathrm{ml}$ fully polymerized, sonicated clot. 
TABLE I

Effect of Inhibitors of ADP-Induced Platelet Aggregation on the Interaction of Polymerizing Human Fibrin with Washed Pig Platelets as Indicated by Changes in Light Transmission Through Suspensions

\begin{tabular}{lccccc}
\hline & & & \multicolumn{3}{c}{ Mean LTU } \\
\cline { 3 - 6 } & & & \multicolumn{3}{c}{$\begin{array}{c}\text { With } \\
\text { in- }\end{array}$} \\
Inhibitor & Final concn. & Expts. & $\begin{array}{c}\text { trol } \\
\text { hibitor }\end{array}$ & $P$ \\
\hline PGE $_{1}$ & $2.9 \times 10^{-4} \mathrm{M}$ & 11 & 43 & 25 & $<0.005$ \\
Apyrase & $0.5 \mathrm{mg} / \mathrm{ml}$ & 10 & 42 & 21 & $<0.005$ \\
\hline
\end{tabular}

ture showed that the platelets were aggregated and that there were fibrin strands interspersed among the platelets (Fig. 4). These platelets had an altered shape and variations in their electron density, but did not appear to have lost their organelles. Occasionally, completely disrupted platelets were seen in the preparations.

Polymerizing fibrin and platelet aggregation. The platelet aggregation seen in these experiments could be due to platelet adherence to polymerizing fibrin or to the release of ADP which caused platelets to stick to each other. To exclude the latter possibility, a concentration of apyrase which inhibited platelet aggregation induced by ADP at a final concentration of $10^{-5} \mathrm{M}$ was added to a suspension of washed pig platelets. It can be seen from Table $I$ that this concentration of apyrase did not block the changes in light transmission induced by polymerizing fibrin. In addition, $\mathrm{PGE}_{1}$, a potent inhibitor of ADP-induced platelet aggregation, did not prevent the changes in light transmission induced by the polymerizing fibrin. Both agents, however, reduced the extent of light transmission changes by about $50 \%$.

The different effects of fibrinogen and of polymerizing fibrin on platelets are illustrated in Fig. 5. Low concentrations of fibrinogen had no effect on the light

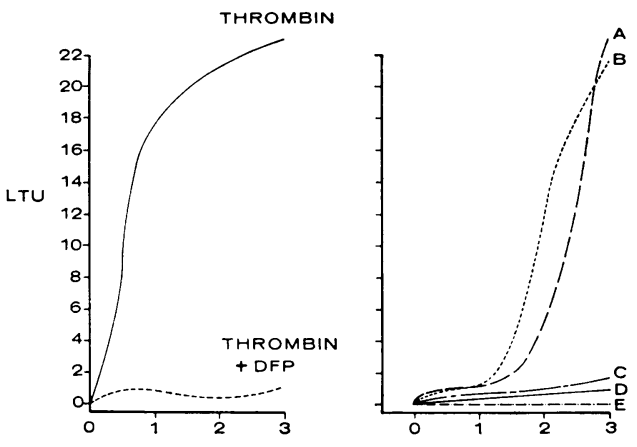

FIGURE 2 Effect of DFP on the aggregation of platelets by thrombin (left) and on the interaction of platelets with polymerizing fibrin (right). Left : $0.1 \mathrm{ml}$ thrombin $(1 \mathrm{U} / \mathrm{ml})$ or $0.1 \mathrm{ml}$ thrombin preincubated with $10^{-3} \mathrm{M}$ DFP for $5 \mathrm{~min}$ were added to $1 \mathrm{ml}$ of pig platelet suspension $\left(10^{8} / \mathrm{mm}^{3}\right)$. Right: $0.2 \mathrm{ml}$ of the incubation mixtures, A, B, C, D, and $E$ were added to $1 \mathrm{ml}$ pig platelet suspension $\left(10^{6} / \mathrm{mm}^{3}\right)$. (A) $10 \mathrm{mg}$ fibrinogen and $0.1 \mathrm{U}$ thrombin incubated in $1.1 \mathrm{ml}$ vol at $37^{\circ} \mathrm{C}$ for $8 \mathrm{~min}$, then reacted for $5 \mathrm{~min}$ with $10^{-8}$ M DFP. (B) The same as "A," but without DFP. (C) Simultaneously incubated fibrinogen, thrombin and DFP over $8 \mathrm{~min}$. Concentrations as in "A." (D) Fibrinogen, and (E) thrombin alone.

transmission of the suspension, but potentiated ADPinduced aggregation in suspensions of pig and human platelets. Incubation of fibrinogen with reptilase gradually destroyed this effect. However, incubation of reptilase with higher concentrations of fibrinogen resulted in the formation of material that caused platelet aggregation when added to a suspension of washed platelets.

Polymerizing fibrin and the platelet-release reaction. To explore further the role of the release of platelet constituents in platelet aggregation seen with polymerizing fibrin, we examined the effects of polymerizing fibrin on the loss of constituents from the platelet granules and cytoplasm. The addition of a mixture of fibrinogen

TABLE II

Adenine Nucleotides, $\mathrm{PF}_{4}$ and ${ }^{3} \mathrm{H}$ Activity Released from Serotonin- ${ }^{3} \mathrm{H}$-Labeled Washed Pig Platelets by Thrombin or Polymerizing Reptilase Fibrin $(R F)$

\begin{tabular}{|c|c|c|c|c|c|c|c|c|c|}
\hline \multirow[b]{3}{*}{ Stimulus } & \multirow[b]{3}{*}{ Expts. } & & & \multicolumn{6}{|c|}{$\%$ of total in supernate } \\
\hline & & \multicolumn{2}{|c|}{ LTU } & \multicolumn{2}{|c|}{$\begin{array}{c}\text { Adenine } \\
\text { nucleotides }\end{array}$} & \multicolumn{2}{|c|}{$\mathrm{PF}_{4}$} & \multicolumn{2}{|c|}{$\begin{array}{c}{ }^{3} \mathrm{H} \\
\text { activity }\end{array}$} \\
\hline & & $\bar{X}$ & SD & $\bar{X}$ & SD & $\bar{X}$ & SD & $\bar{X}$ & SD \\
\hline (1) $0.1 \mathrm{U}$ thrombin (final concn.) & 4 & 41 & 6.5 & 41.6 & 8.9 & 50 & 20.4 & 58 & 15.3 \\
\hline (2) $\mathrm{RF}$ (15 min incubn.) & 4 & 30 & 12.1 & 8.8 & 3.8 & 8 & 4.7 & 4.8 & 4.7 \\
\hline (3) Control & 4 & 0 & - & 0 & - & 0 & 一 & 1.2 & 1.3 \\
\hline$P$ for (1) vs. (2) & & \multicolumn{2}{|c|}{$<0.05$} & \multicolumn{2}{|c|}{$<0.0005$} & \multicolumn{2}{|c|}{$<0.01$} & \multicolumn{2}{|c|}{$<0.0005$} \\
\hline
\end{tabular}


and reptilase to a suspension of washed pig platelets labeled with serotonin ${ }^{8} \mathrm{H}$ caused the loss of about $5 \%$ of the platelet radioactivity (Table II). In these experiments, about $9 \%$ of the adenine nucleotides and
$8 \%$ of the $\mathrm{PF}_{4}$ were lost into the supernatant fluid. Thrombin, which caused about the same degree of change in light transmission as the polymerizing reptilase-fibrin, caused release of $42 \%$ of the platelet adenine
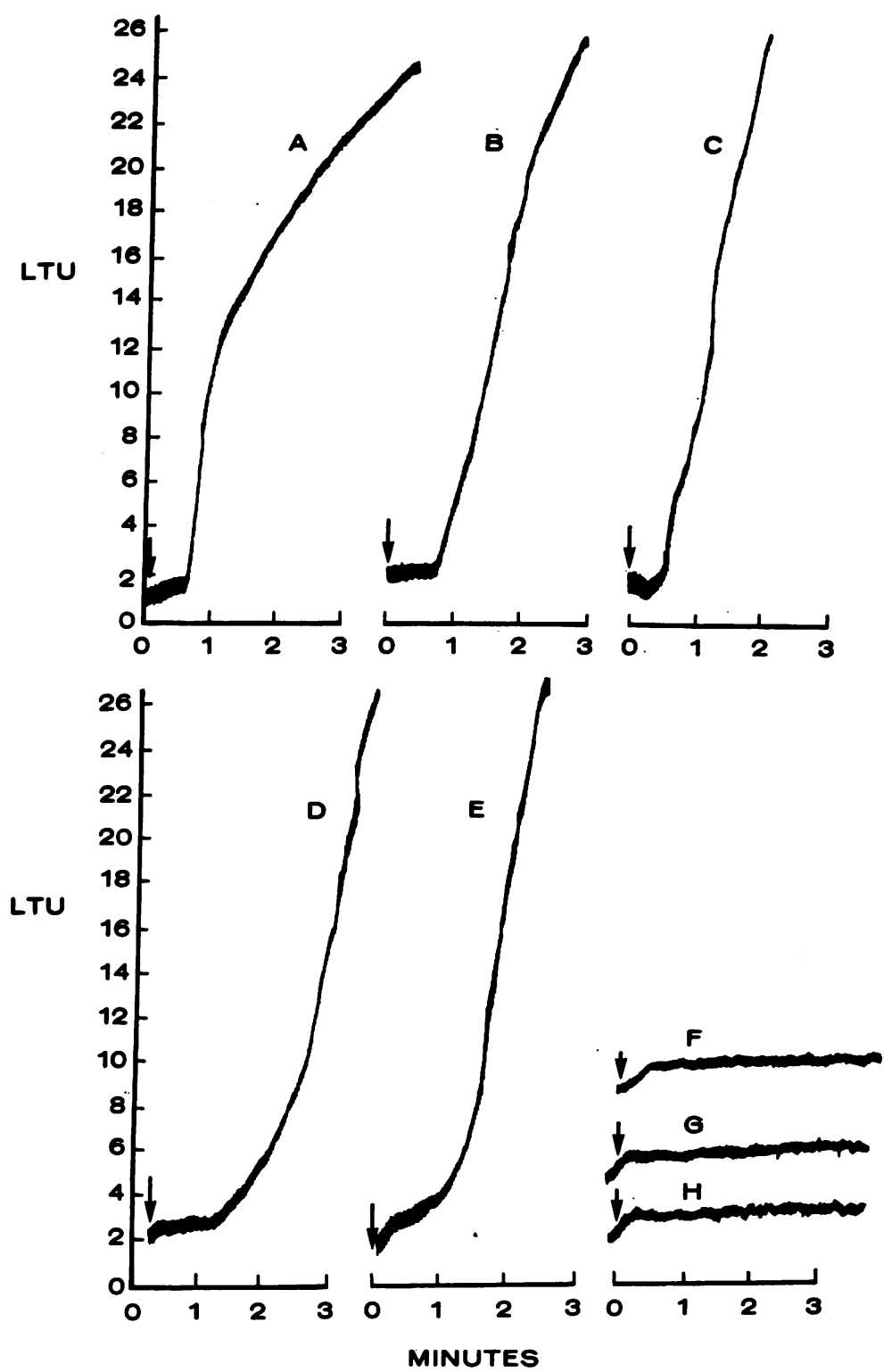

FIGURE 3 Light transmission through platelet suspensions from three different species after their exposure to fibrinogen or polymerizing reptilase fibrin from different species. The start of the experiments is indicated by an arrow. (A), human fibrinogen and reptilase (12 $\mathrm{min}$ incubation) added to human platelets, (B), human fibrinogen and reptilase (15 min incubation) + rabbit platelets, (C), human fibrinogen and reptilase (14 min incubation) + pig platelets, (D), pig fibrinogen and reptilase ( $4 \mathrm{~min}$ incubation) + pig platelets, $(\mathrm{E})$, bovine fibrinogen and reptilase (10 min incubation) + pig platelets, (F), human fibrinogen + pig platelets, $(G)$, pig fibrinogen + pig platelets, $(H)$, bovine fibrinogen + pig platelets. 


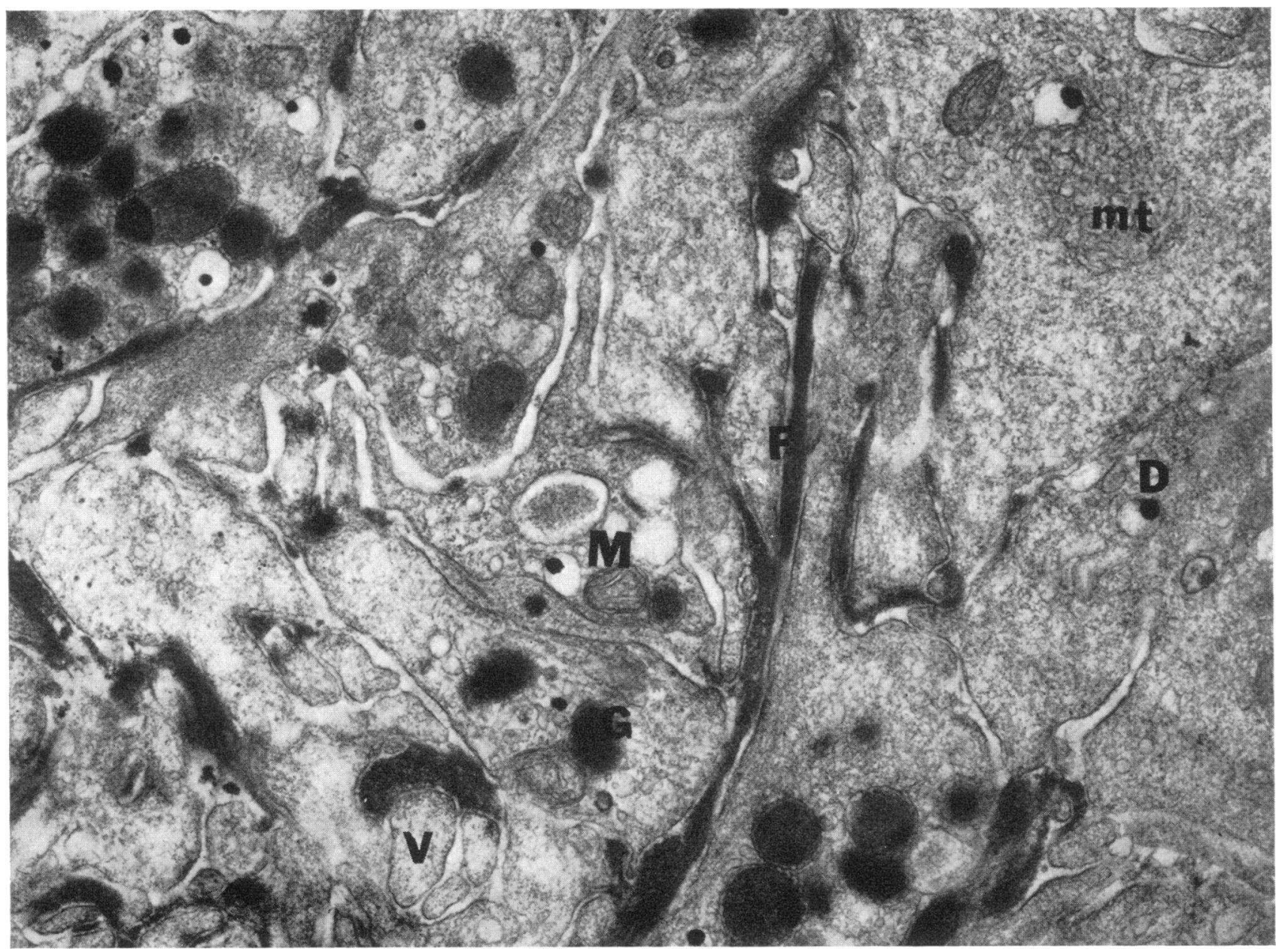

FIgURE 4 Thin section of rabbit platelets after exposure to polymerizing reptilase fibrin for 3 min. Incubation of fibrinogen with reptilase was 15 min. Note the fibrin (F) interspersed among the aggregated platelets. The loss of electron density may be due to platelet swelling and pseudopod formation or to some loss of cytoplasmic constituents. M, mitochondrion; G, granule ; $\mathrm{V}$, vesicle; $\mathrm{mt}$, microtubule; $\mathrm{D}$, dense body. Magnification $\times 40,400$.

nucleotides, $50 \%$ of the $\mathrm{PF}_{4}$, and $58 \%$ of the ${ }^{8} \mathrm{H}$-radioactivity into the supernatant fluid (Table II).

To study whether the polymerizing fibrin caused loss of platelet cytoplasmic constituents, we examined the effect of polymerizing reptilase-fibrin on the loss of lactic dehydrogenase from washed rabbit platelets. The results shown in Table III demonstrate that about $4 \%$ of the platelet lactic dehydrogenase was lost into the supernatant fluid. In this experiment, about $5 \%$ of the radioactivity was also released. In contrast, thrombin, in a concentration which caused the same extent of change in light transmission, released $85 \%$ of the platelet radioactivity into the supernatant fluid and about $4 \%$ of the platelet lactic dehydrogenase. The effect of $\mathrm{PGE}_{1}$ on the loss of radioactivity into the supernatant fluid from serotonin ${ }^{8} \mathrm{H}$-labeled washed pig platelets was examined. The results shown in Table IV demonstrate that $\mathrm{PGE}_{1}$ did diminish the amount of radioactivity released. This Table also shows that fibrinogen or reptilase incubated with platelets did not cause any appreciable release of radioactivity.

The effect of polymerizing thrombin-fibrin on the release of radioactivity from washed pig platelets labeled with serotonin- ${ }^{8} \mathrm{H}$ was also examined. When platelets labeled with serotonin- ${ }^{3} \mathrm{H}$ interacted with polymerizing thrombin-fibrin they released radioactivity (Table V). This was inhibited by the addition of hirudin, heparin, or DFP at the beginning, or after $8 \mathrm{~min}$ of fibrin polymerization. The changes in light transmission were affected significantly by thrombin inhibitors only if they were added to the fibrinogen solution at the same time as thrombin. 
TABLE III

Release of Lactic Dehydrogenase $(L D H)$ and $5-H T{ }^{3} \mathrm{H}$ from Washed Rabbit Platelets by Thrombin or by Polymerizing Reptilase Fibrin $(R F)$

\begin{tabular}{|c|c|c|c|c|c|c|c|}
\hline \multirow[b]{3}{*}{ Stimulus } & \multirow[b]{3}{*}{ Expts. } & & & \multicolumn{4}{|c|}{$\%$ of total in supernate } \\
\hline & & \multicolumn{2}{|c|}{ LTU } & \multicolumn{2}{|c|}{$5-\mathrm{HT}-{ }^{-3} \mathrm{H}$} & \multicolumn{2}{|c|}{ LDH } \\
\hline & & $\bar{X}$ & SD & $\bar{X}$ & SD & $\bar{X}$ & SD \\
\hline (1) $0.1 \mathrm{U}$ thrombin (final concn.) & 3 & 43 & 10.4 & 85.8 & 4.0 & 2.5 & 1.6 \\
\hline (2) RF (15 min incubn.) & 7 & 39 & 12.1 & 4.6 & 2.2 & 3.9 & 2.9 \\
\hline (3) Control & 4 & 0 & - & 1.2 & 0.1 & 0.3 & $<0.1$ \\
\hline$P$ for (1) vs. (2) & & \multicolumn{2}{|c|}{$<0.5$} & \multicolumn{2}{|c|}{$<0.0005$} & \multicolumn{2}{|c|}{$<0.4$} \\
\hline
\end{tabular}

Association of polymerizing fibrin with platelets. To examine the interaction of the polymerizing fibrin with washed platelets, we studied the amount of ${ }^{125} \mathrm{I}$-labeled

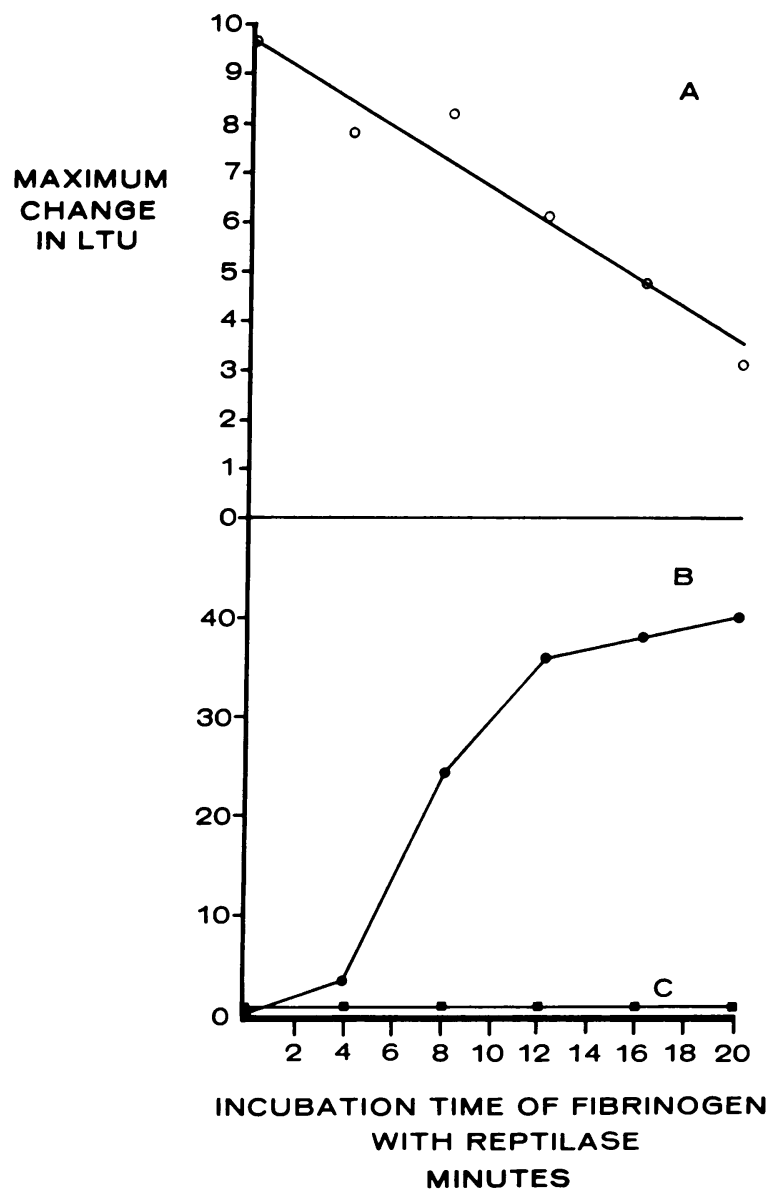

FIGURE 5 Comparison of the effect of fibrinogen and polymerizing fibrin on platelets. Polymerizing fibrin: $0.9 \mathrm{ml} 1 \%$ fibrinogen and $0.1 \mathrm{ml} 0.3 \%$ reptilase were incubated for various intervals. (A), $0.02 \mathrm{ml}$ polymerizing fibrin + $0.1 \mathrm{ml}$ ADP $\left(10^{-5} \mathrm{M}\right)$ added to $1 \mathrm{ml}$ of pig platelets $\left(10^{8} / \mathrm{mm}^{8}\right)$. Coefficient of correlation $=-0.975$. (B), $0.2 \mathrm{ml}$ polymerizing fibrin added to $1 \mathrm{ml}$ of pig platelets. (C), $0.02 \mathrm{ml}$ polymerizing fibrin added to $1 \mathrm{ml}$ of pig platelets. fibrin that became associated with the platelets. When labeled polymerizing reptilase-fibrin was added to a suspension of washed pig platelets, more radioactivity was found in the sediment than in a control experiment performed with the platelet-free suspending medium (Table VI). The amount of radioactivity found in the pellet as well as the extent of change in light transmission depended on the incubation time of the reptilasefibrinogen mixture before it was added to the platelet suspension. Despite the fact that the larger changes in light transmission were frequently accompanied by a greater accumulation of radioactivity in the pellet, the correlation between these two variables was poor $(r=$ +0.37 and +0.49 using material from shorter and longer polymerizations, respectively). Similar results were obtained using a mixture of thrombin and ${ }^{125} \mathrm{I}$ labeled fibrinogen. In these experiments, the thrombin was inhibited with hirudin (after $8 \mathrm{~min} 36 \mathrm{U}$ hirudin was added to $1.0 \mathrm{ml}$ polymerizing fibrin).

Since it is possible that the platelets sedimenting under centrifugal forces could trap small fibers of poly-

TABLE IV

Loss of Radioactivity from Serotonin- ${ }^{3} \mathrm{H}$-Labeled Washed Pig Platelets Exposed to Human Fibrinogen, Reptilase, or Polymerizing Reptilase-Fibrin $(R F)$ with and without $P G E_{1}$

\begin{tabular}{lccc}
\hline & & \multicolumn{2}{c}{$\begin{array}{c}\% \text { of incorporated } \\
\text { 3H activity in } \\
\text { supernate }\end{array}$} \\
\cline { 3 - 5 } \multicolumn{1}{c}{ Material added* } & & $\bar{X}$ & sD \\
\hline Tyrode & Expts. & 1.2 & 1.3 \\
Human fibrinogen $(1 \%)$ & 14 & 1.8 & 1.3 \\
Reptilase $(0.03 \%)$ & 14 & 1.4 & 1.0 \\
Reptilase $(3 \%)$ & 7 & 1.2 & 0.7 \\
RF (15 min incubn.) & 14 & $6.0 \ddagger$ & 4.7 \\
RF (15 min incubn.) & & & \\
$+\quad+$ PGE $1\left(2.9 \times 10^{-4} \mathrm{M}\right)$ & 6 & 1.6 & 0.8 \\
\hline
\end{tabular}

* In each case, $0.4 \mathrm{ml}$ was added to $10^{\circ}$ platelets in $1 \mathrm{ml}$. $\ddagger$ Significantly different $(P<0.01)$ from the other means.

Platelet Interaction with Polymerizing Fibrin 
TABLE V

Effect of Thrombin Inhibitors on the Release of Serotonin ${ }^{3} \mathrm{H}$ from Washed Pig Platelets Interacting with Polymerizing Thrombin-Fibrin

\begin{tabular}{|c|c|c|c|c|}
\hline \multicolumn{2}{|c|}{$\begin{array}{l}\text { Inhibitor added to } \\
\text { polymerizing fibrin }\end{array}$} & \multirow{2}{*}{$\begin{array}{l}\text { Time } \\
\text { of } \\
\text { addi- } \\
\text { tion }\end{array}$} & \multirow[b]{2}{*}{ LTU } & \multirow{2}{*}{$\begin{array}{l}\text { Incorporated } \\
{ }^{3} \mathrm{H} \text { activity } \\
\text { released }\end{array}$} \\
\hline Type & $\begin{array}{l}\text { Final } \\
\text { concn. }\end{array}$ & & & \\
\hline Contral & & $\min *$ & & $\%$ \\
\hline (Tyrode) & - & 8 & 39 & 19.4 \\
\hline Heparin & $23 \mathrm{U} / \mathrm{ml}$ & 0 & 1 & 1.1 \\
\hline Heparin & $23 \mathrm{U} / \mathrm{ml}$ & 8 & 26 & 2.6 \\
\hline Hirudin & $36 \mathrm{U} / \mathrm{ml}$ & 0 & 2 & 1.5 \\
\hline Hirudin & $36 \mathrm{U} / \mathrm{ml}$ & 8 & 33 & 1.6 \\
\hline DFP & $10^{-3} \mathrm{M}$ & 0 & 1 & 2.0 \\
\hline DFP & $10^{-3} \mathrm{M}$ & 8 & 36 & 5.1 \\
\hline
\end{tabular}

* In each case, $0.02 \mathrm{U}$ thrombin was preincubated with $10 \mathrm{mg}$ fibrinogen in $1 \mathrm{ml}$ for $8 \mathrm{~min} ; 0.1 \mathrm{ml}$ of inhibitor solution was added before or after incubation, and $0.2 \mathrm{ml}$ of this mixture was tested 5 min later on $10^{9}$ platelets contained in $1 \mathrm{ml}$. Data in this table is a representative set out of five experiments.

merizing fibrin and remove them in this way rather than as the result of specific interaction, control studies were performed in which dextran particles ( $80 \mu$ average diameter, $8.3 \mathrm{mg} /$ sample) were substituted for platelets. The radioactivity of the sediments obtained from the platelet-free suspending medium and the medium containing the particles were the same.

Electron microscopic investigations by means of the shadow-casting technique demonstrated that polymerizing fibrin added to platelet suspending medium without platelets was composed of small fibrils (Fig. 6). In the presence of platelets, strands that were many times larger were formed. They were intimately associated with platelets; in many cases they could be seen extending over the surface of the platelets. Platelets were entrapped in a fibrin net (Fig. 7). In some instances, fibrin strands appeared to be closely associated with platelet pseudopods (Fig. 8). Formation of fibrin strands and their association with platelets occurred immediately after addition of polymerizing fibrin to the platelet suspension and before detectable changes in light transmission. Thin sections showed a close association between the fibrin and the aggregated platelets (Fig. 4).

The effect of EDTA or EGTA on the interaction of washed platelets with polymerizing fibrin. When polymerizing reptilase-fibrin was added to a platelet suspension containing EDTA or EGTA in concentrations adequate to chelate calcium and magnesium, there was virtually no change in light transmission and no association of radioactivity with the platelet pellet (Table VII). The addition of a polymerizing thrombin-fibrin solution, in which thrombin action was stopped beforehand with an excess of hirudin, to a suspension of washed pig platelets containing EDTA caused little increase in light transmission and in radioactivity associated with the platelets (Table VII). The inhibitory effect of EDTA was reversible by an excess of calcium but not by magnesium. Electron microscopy showed that in these experiments with EDTA the fibrin strands were small and that there were no detectable fibrils associated with platelet membranes (Fig. 9).

Other factors infuencing association of polymerizing fibrin with platelets. Table VIII shows that apyrase and $\mathrm{PGE}_{1}$ diminished the changes of light transmission occurring during the interaction of platelets with polymerizing fibrin, while the amount of radioactivity from ${ }^{125}$ I-labeled fibrinogen recovered in the platelet sediment was increased. Electron microscopic studies also showed that $\mathrm{PGE}_{1}$ did not interfere with the formation of fibrin strands or their association with platelet membranes (Fig. 10a,b).

TABLE VI

Changes in Light Transmission Units (LTU) during Incubation and Percentage of Total Radioactivity Removed by Centrifugation from Solutions of Polymerizing Reptilase Fibrin-125I with and without the Presence of Washed Pig Platelets

\begin{tabular}{|c|c|c|c|c|c|c|c|c|}
\hline \multirow{3}{*}{$\begin{array}{l}\text { Polymeri- } \\
\text { zation } \\
\text { time }\end{array}$} & \multirow[b]{3}{*}{ Expts. } & & & \multicolumn{4}{|c|}{ Radioactivity in sediment } & \multirow[b]{3}{*}{$P$} \\
\hline & & \multicolumn{2}{|c|}{ LTU } & \multicolumn{2}{|c|}{$\begin{array}{l}\text { without } \\
\text { platelets }\end{array}$} & \multicolumn{2}{|c|}{$\begin{array}{l}\text { with } \\
\text { platelets }\end{array}$} & \\
\hline & & $\bar{X}$ & SD & $\bar{X}$ & SD & $\bar{X}$ & SD & \\
\hline $\min$ & & & & & & & & \\
\hline $5-10$ & 14 & 6 & 13 & 1.2 & 0.5 & 4.4 & 3.2 & $<0.0005$ \\
\hline $10-16$ & 17 & 51 & 56 & 3.7 & 3.4 & 14.9 & 8.5 & $<0.0005$ \\
\hline
\end{tabular}




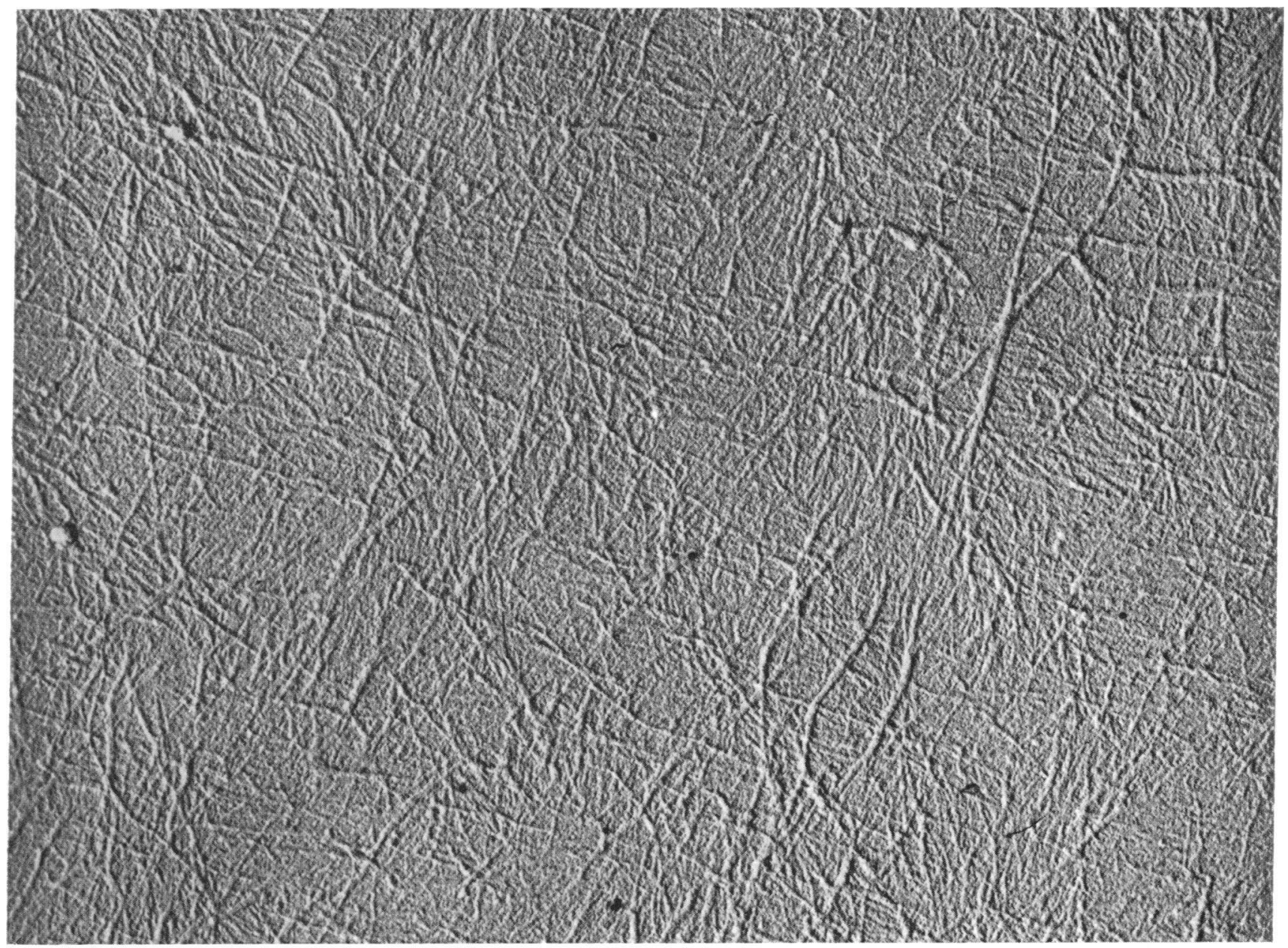

Figure 6 Polymerizing reptilase fibrin. Human fibrinogen was incubated with reptilase for $15 \mathrm{~min}$ at $37^{\circ} \mathrm{C}$ before fixation. The fibrils are approximately $0.5-2 \mu$ long and less than $0.05 \mu$ wide. Magnification $\times 33,600$.

\section{DISCUSSION}

The experiments reported in this paper show that suspensions of washed platelets prepared from human, pig, or rabbit blood adhere to polymerizing fibrin and that this may cause platelets to adhere to each other. This effect could be produced by fibrin polymerized by thrombin or reptilase. Since reptilase in contrast to thrombin does not induce the platelet-release reaction and platelet aggregation, it was possible to use the reptilase-treated fibrinogen for most of these studies and thereby exclude the effects of the thrombin-induced platelet-release reaction. Platelets interacting with the mixture of reptilase and fibrinogen lost very little of their granular and cytoplasmic constituents, and this loss did not appear to be the result of platelet-release reaction. Inhibitors of the platelet-release reaction or ADP-induced platelet aggregation did not prevent the interaction of platelets with the polymerizing fibrin, demonstrating that this reaction does not require the action of ADP or the platelet-release reaction.

Electron microscopic examination showed the platelets aggregated by the polymerizing fibrin to be adherent to each other with fibrin strands interspersed among the platelets; the fibrin appeared to be in close association with the platelet membranes. The platelets had altered their shape and there were some slight variations in electron density but the platelets did not appear to have lost their organelles. Electron microscopic observations of the shadow-cast preparations suggested that platelets promote the polymerization of fibrin since the fibrin strands were longer and larger than in the preparations without platelets. In addition, it appeared that the polymerizing fibrin tended to become associated with the platelet pseudopods.

Platelet Interaction with Polymerizing Fibrin 


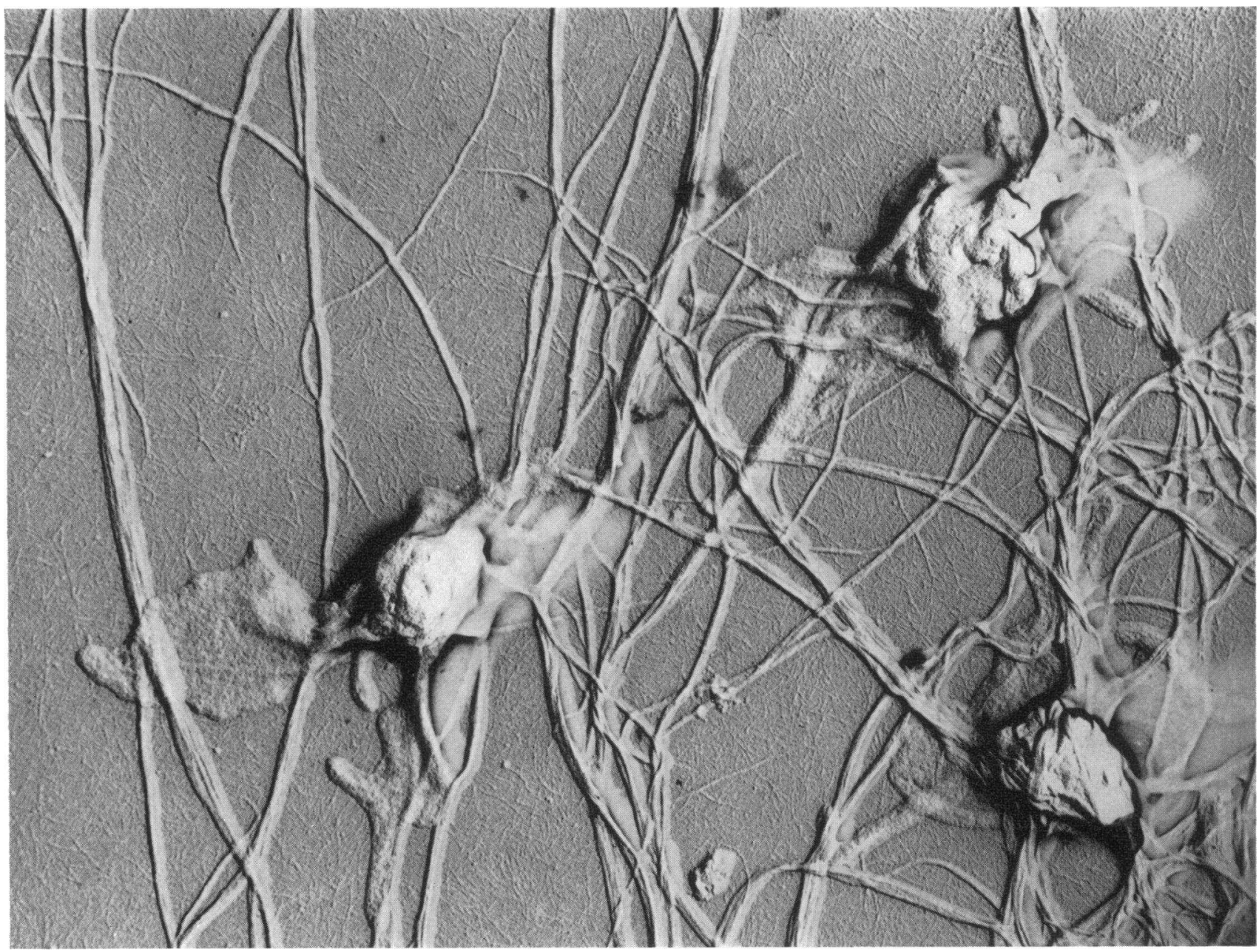

FIGURE 7 Interaction of rabbit platelets with polymerizing reptilase fibrin. Incubation of fibrinogen with reptilase as in Fig. 6. Platelets were exposed to this mixture for $30 \mathrm{sec}$. Note the large fibrin strands (which are absent in Fig. 6) connecting platelets at considerable distances. Magnification $\times 14,000$.

In these experiments, small amounts of ADP were lost from the platelets when they were exposed to polymerizing fibrin. The addition of $\mathrm{PGE}_{1}$ to the platelet suspension diminished the extent of platelet aggregation. Apyrase also diminished the same. It seems reasonable to conclude that the extent of light transmission changes seen in the presence of these compounds was due to the platelet adherence to polymerizing fibrin.

In the experiments with fibrinogen ${ }^{125} I$, the association of washed human, pig, or rabbit platelets with polymerizing fibrin was not blocked by any of the known inhibitors of platelet aggregation or the platelet-release reaction, such as apyrase or PGE. However, the interaction of the washed platelets with polymerizing fibrin was dependent upon the presence of calcium. While there is some evidence that calcium is required for platelet adherence to surfaces such as glass, all the evidence seems to suggest that calcium is not required for platelet adhesion to collagen (20). Recently it has been found that divalent cations are necessary for platelet adherence to fibrin-coated surfaces (21). This may indicate that the mechanisms by which platelets adhere to polymerizing fibrin is different from that by which they adhere to collagen.

The nature of the material on the surface of the platelet which interacts with polymerizing fibrin is not known. Involvement of $\mathrm{PF}_{4}$, a factor enhancing fibrinmonomer polymerization (22), is unlikely since this factor is located in platelet granules and its release during interaction with polymerizing fibrin is very limited. Fibrinogen is known to be associated with the surface of platelets (8) and it is believed to be involved 


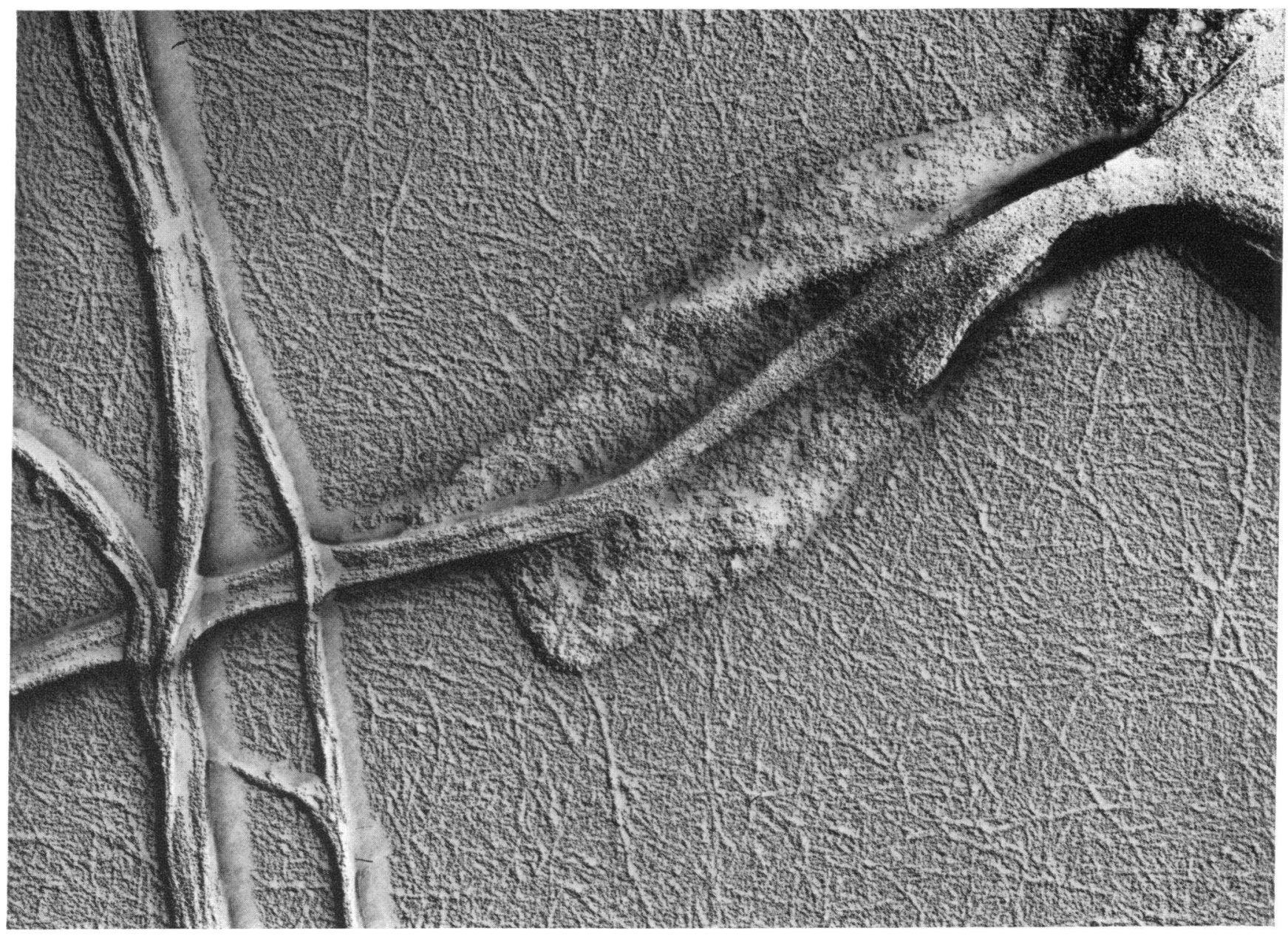

Figure 8 Detail from a preparation similar to the one pictured in Fig. 7 showing the close association between platelet pseudopod and a fibrin strand. Magnification $\times 43,900$.

TABLE VII

Effect of EGTA or EDTA on the Interaction of Washed Pig Platelets* with Polymerizing Reptilase-Fibrin-125I $(R F)$ or Polymerizing Thrombin-Fibrin-125I (TF)

\begin{tabular}{|c|c|c|c|c|c|c|c|c|c|c|c|}
\hline \multirow[b]{3}{*}{ Chelating agent } & \multirow{3}{*}{$\begin{array}{l}\text { Type and } \\
\text { No. of } \\
\text { expts. }\end{array}$} & \multicolumn{4}{|c|}{ LTU } & \multicolumn{4}{|c|}{ Radioactivity in sediment } & \multirow{2}{*}{\multicolumn{2}{|c|}{$P$}} \\
\hline & & \multicolumn{2}{|c|}{$\begin{array}{l}\text { without } \\
\text { chelator }\end{array}$} & \multicolumn{2}{|c|}{$\begin{array}{c}\text { with } \\
\text { chelator }\end{array}$} & \multicolumn{2}{|c|}{$\begin{array}{l}\text { without } \\
\text { chelator }\end{array}$} & \multicolumn{2}{|c|}{$\begin{array}{l}\text { with } \\
\text { chelator }\end{array}$} & & \\
\hline & & $\bar{X}$ & SD & $\bar{X}$ & sD & $\bar{X}$ & SD & $\bar{X}$ & SD & LTU & ${ }^{125} \mathrm{I}$ \\
\hline & & & & & & \multicolumn{4}{|c|}{$\%$} & & \\
\hline EGTA $\left(5 \times 10^{-3} \mathrm{M}\right)$ & $\mathrm{RF}, 3$ & 63 & 19 & 0.6 & 0.5 & - & - & - & - & $<0.025$ & 一 \\
\hline EDTA $\left(5 \times 10^{-3} \mathrm{M}\right)$ & $\mathrm{RF}, 6$ & 52 & 30 & 0.9 & 0.7 & 20.4 & 12.9 & 3.2 & 4.0 & $<0.025$ & $<0.01$ \\
\hline \multicolumn{12}{|l|}{ EDTA $\left(5 \times 10^{-3} \mathrm{M}\right)$} \\
\hline no platelets & RF, 8 & - & - & - & - & 3.6 & 2.7 & 1.2 & 0.4 & - & $<0.05$ \\
\hline EDTA $\left(6 \times 10^{-3} \mathrm{M}\right)$ & $\mathrm{TF}, 6$ & 24 & 11 & 1.5 & 1.5 & 9.4 & 3.4 & 5.1 & 3.6 & $<0.005$ & $<0.01$ \\
\hline \multicolumn{12}{|l|}{ EDTA $\left(6 \times 10^{-3} \mathrm{M}\right)$} \\
\hline no platelets & TF, 6 & - & - & - & - & 5.3 & 2.9 & 3.6 & 2.5 & - & $<0.1$ \\
\hline
\end{tabular}

* The platelet suspending fluid contained $\mathrm{Ca}^{++} 2 \times 10^{-3} \mathrm{M}$ and $\mathrm{Mg}^{++} 10^{-3} \mathrm{M}$. 
in the adherence of platelets to each other during ADPinduced platelet aggregation (23-26). Although polymerizing fibrin can cause light transmission changes of platelet suspension, its ability to potentiate ADP- induced platelet aggregation is considerably decreased as compared with fibrinogen. The effects of fibrinogen and of polymerizing fibrin are likely related to different mechanisms.

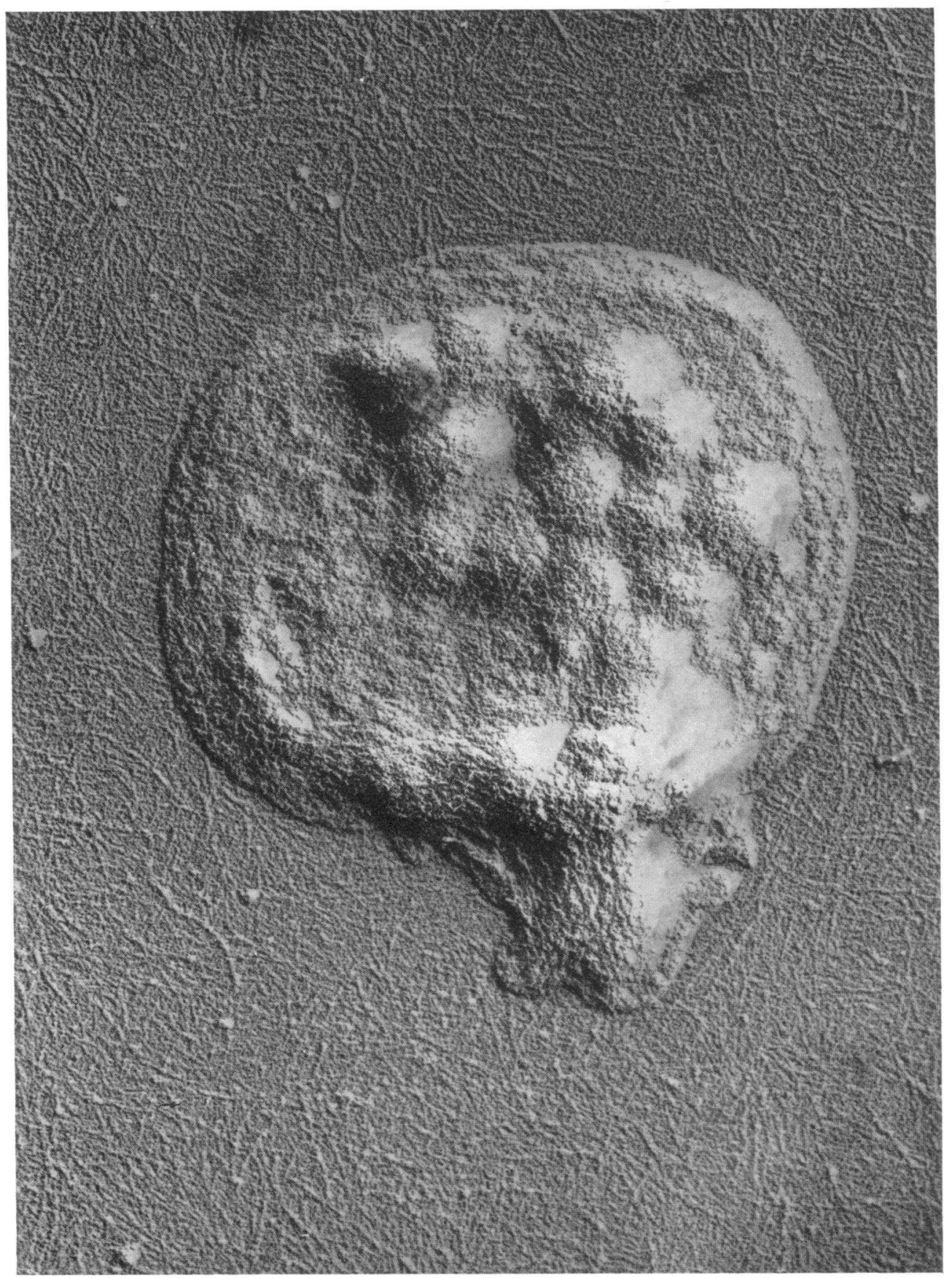

FIGURE 9 Lack of interaction of rabbit platelet with polymerizing reptilase fibrin in the presence of $0.5 \times 10^{-2} \mathrm{M}$ EDTA. Fibrinogen was first incubated with reptilase for $15 \mathrm{~min}$, then mixed with platelets for $3 \mathrm{~min}$. Pseudopod formation, promotion of polymerization, and association of fibrils with the platelets are absent. Magnification $\times 37,400$. 
TABLE VIII

Effect of Inhibitors of Platelet Aggregation or the Release Reaction on the Interaction of Polymerizing Reptilase Fibrin-125I with Washed Pig Platelets

\begin{tabular}{|c|c|c|c|c|c|c|c|c|c|c|c|c|}
\hline \multirow{2}{*}{\multicolumn{2}{|c|}{ Inhibitor }} & \multirow[b]{3}{*}{ Expts. } & \multicolumn{4}{|c|}{ LTU } & \multicolumn{4}{|c|}{ Radioactivity in sediment } & \multirow{2}{*}{\multicolumn{2}{|c|}{$P$}} \\
\hline & & & \multicolumn{2}{|c|}{$\begin{array}{l}\text { Without } \\
\text { inhibitor }\end{array}$} & \multicolumn{2}{|c|}{$\begin{array}{c}\text { With } \\
\text { inhibitor }\end{array}$} & \multicolumn{2}{|c|}{$\begin{array}{l}\text { Without } \\
\text { inhibitor }\end{array}$} & \multicolumn{2}{|c|}{$\begin{array}{c}\text { With } \\
\text { inhibitor }\end{array}$} & & \\
\hline Type & Final conen. & & $\bar{X}$ & SD & $\bar{X}$ & SD & $\bar{X}$ & SD & $\bar{X}$ & SD & LTU & 125I \\
\hline & & & & \multicolumn{9}{|c|}{$\%$} \\
\hline Apyrase & $0.5 \mathrm{mg} / \mathrm{ml}$ & 3 & 62 & - & 25 & - & 23.4 & 一 & 28.4 & - & - & - \\
\hline $\mathrm{PGE}_{1}$ & $2.9 \times 10^{-4} \mathrm{M}$ & 11 & 43 & 35 & 25 & 22 & 12.0 & 9.6 & 14.9 & 9.6 & $<0.005$ & $<0.25$ \\
\hline \multicolumn{13}{|l|}{$\mathrm{PGE}_{1}$, no } \\
\hline platelets & $2.9 \times 10^{-4} \mathrm{M}$ & 11 & - & - & 一 & - & 3.7 & 3.0 & 4.1 & 4.6 & - & $<0.5$ \\
\hline
\end{tabular}

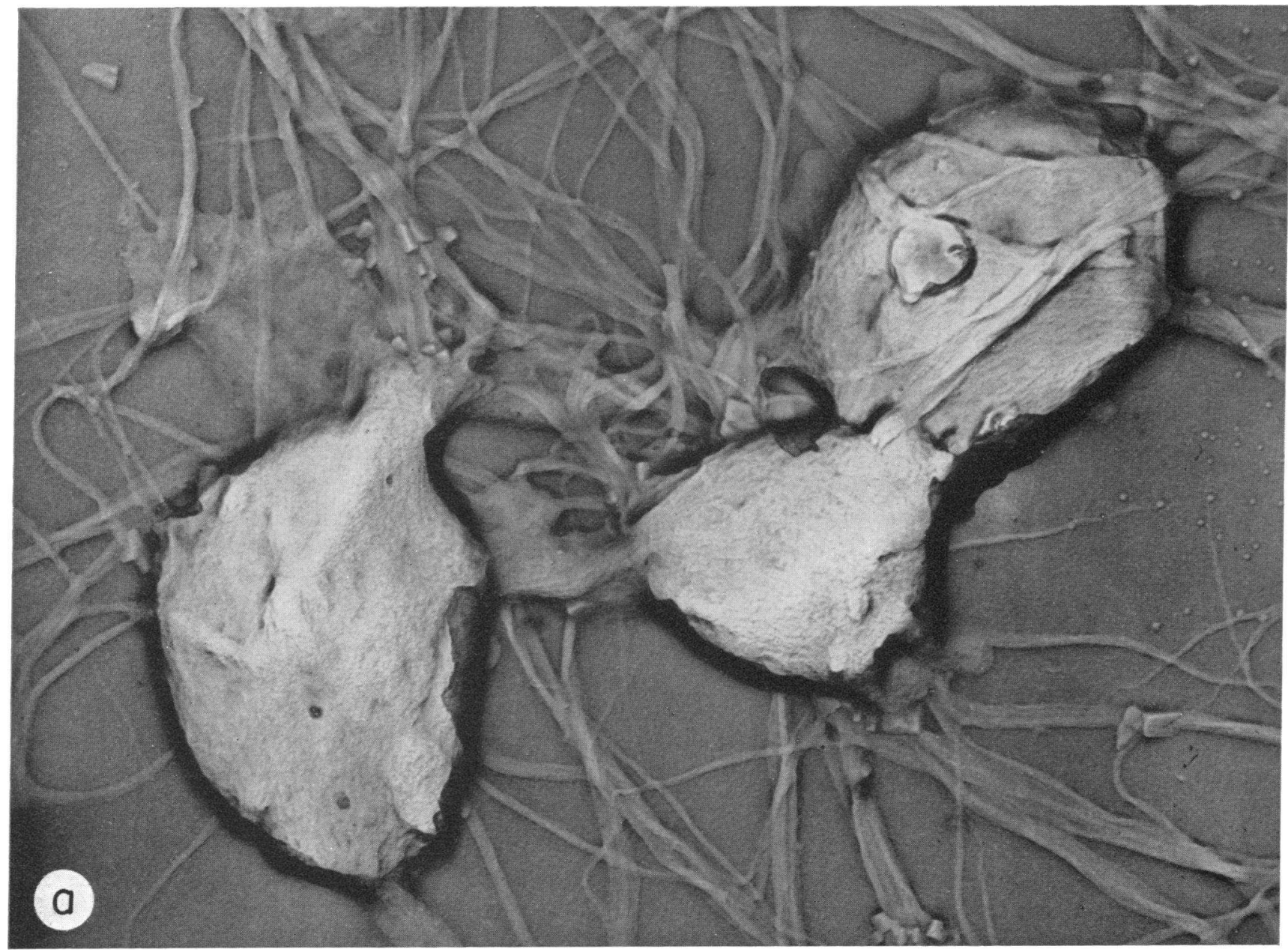

FIGURE 10 Interaction of platelets with polymerizing reptilase fibrin in the presence of $\mathrm{FGE}_{1}$ $\left(29 \times 10^{-6} \mathrm{M}\right)$. The incubation time of reptilase with fibrinogen was $15 \mathrm{~min}$. (a), Rabbit platelets are closely associated with fibrin strands and trapped in a fibrin net (shadow-casting technique; magnification $\times 20,800)$. (b), The aggregation of pig platelets is inhibited but fibrin strands are closely associated with membranes (thin sectioning technique; magnification $\times 28,350$ ).

(FIgURE $10 \mathrm{~b}$, continued on page 698) 


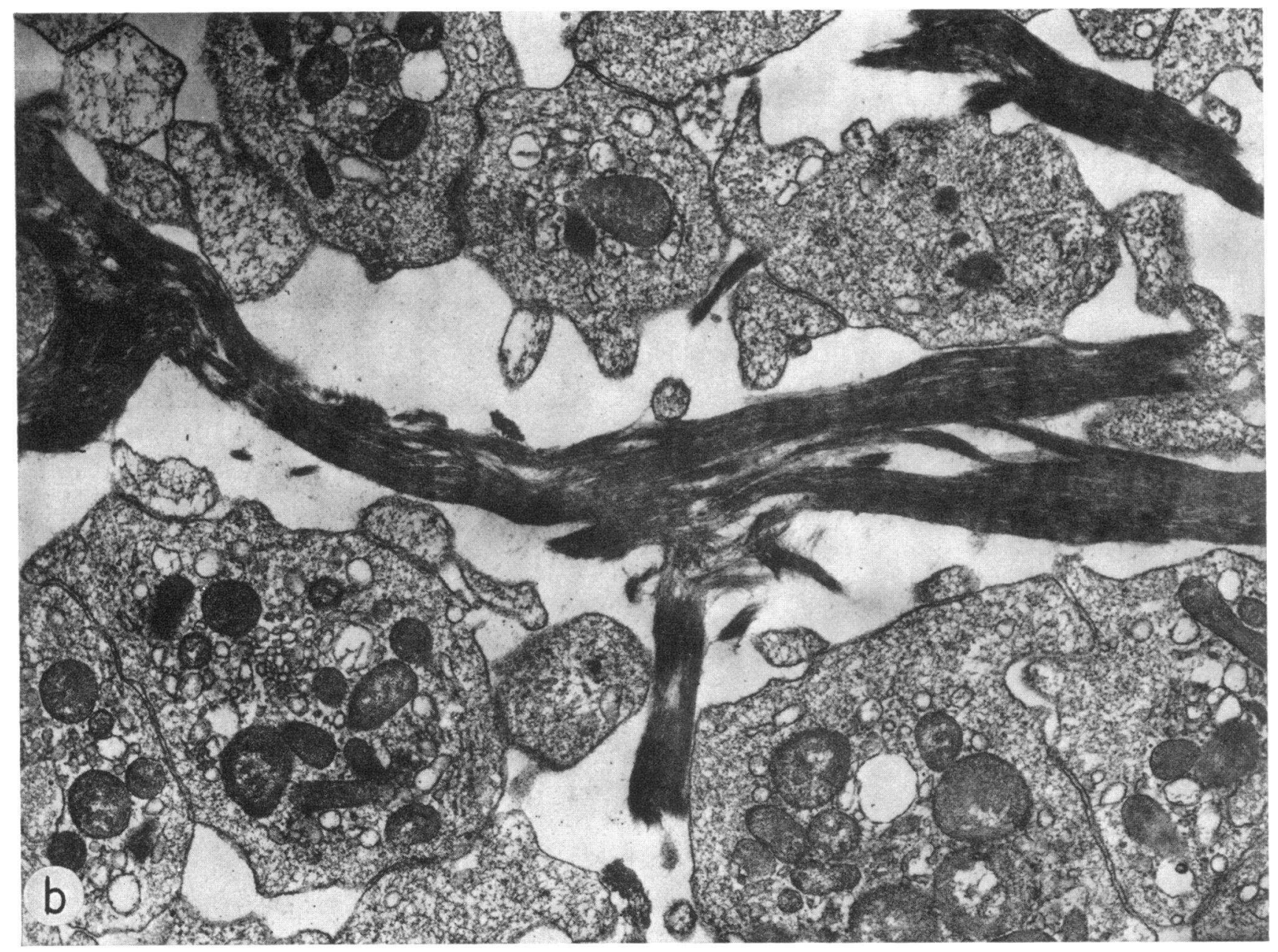

Figure $10 \mathrm{~b}$.

The failure of platelets to adhere to fully polymerized fibrin suggests that there are sites available during the polymerization of fibrin which can interact with platelets and that these are lost after full polymerization.

Kopec et al. (27) and Larrieu, Rigollot, and Kubise (28) described platelet aggregation caused by soluble complexes of fibrin monomer with fibrinogen-degradation products. In addition, Kopec et al. (27) found that complexes of fibrin monomers with fibrinogen have a similar effect and that platelets cause precipitation of fibrin from the complexes. It is possible that some of the platelet aggregates seen in these studies may have been caused by fibrin polymerization induced by the platelet suspensions. Solum's observation, that bovine fibrinogen-aggregated washed suspensions of human platelets, (29), might have a similar explanation. Mixing the platelet suspensions and fibrinogen solutions used in our studies did not cause platelet aggregation.
The interaction of platelets with polymerizing fibrin may be important in the establishment of stable hemostatic plugs and thrombi. The close association between platelets and fibrin, in hemostatic plugs and in thrombi formed in vivo or artificially in vitro have been reported by a number of investigators $(30-35)$. We have the impression from the present study that the fibrin strands may have a predilection to be associated with the platelet pseudopods. This may be important in clot retraction and Sokal (36) has suggested that contraction of the platelet pseudopods is responsible for clot retraction. Microfilaments have been identified in pseudopods (37) and it is conceivable that this material represents platelet thrombosthenin.

It is generally assumed that the injury to the vessel wall leads to exposure of subendothelial structures such as collagen (20) or elastic microfibrils (38) with which 
the platelets interact. Ashford and Frieman (39) have shown that minimal damage to the vessel wall can lead to endothelial injury with fibrin formation. Their data may indicate that the fibrin formation occurred first and the platelets subsequently adhered to the fibrin. The results from the present study suggested that the platelets could adhere to the polymerizing fibrin on the vessel wall.

\section{ACKNOWLEDGMENTS}

We wish to thank Mr. T. Bistricki, Mr. K. L. Wong, and Mrs. D. Blondowska for skilled technical assistance.

The investigation was supported by grants from the Ontario Heart Foundation and the Medical Research Council of Canada (grants MA-4074 and MT-1309).

\section{REFERENCES}

1. Hovig, T., L. Jørgensen, M. A. Packham, and J. F. Mustard. 1968. Platelet adherence to fibrin and collagen. J. Lab. Clin. Med. 71:29.

2. Apitz, K. 1939. Uber profibrin. VI. Die agglutination von blutplättchen durch profibrin. Z. Gesamte Exp. Med. 105: 89 .

3. Solum, N. O. 1966. Platelet aggregation during fibrin polymerization. Scand. J. Clin. Lab. Invest. 18: 577.

4. Niewiarowski, S., J. V. Ream, and D. P. Thomas. 1970. Effect of fibrinogen derivatives on platelet aggregation. Thromb. Diath. Haemorrh. Suppl. 42: 49.

5. Blombäck, B., and M. Blombäck. 1957. Purification of human and bovine fibrinogen. Ark. Kemi. 10: 415.

6. Regoeczi, E., and B. A. Stannard. 1969. In vivo behaviour of frozen and freeze-dried fibrinogen and of that prepared from out-dated blood. Biochim. Biophys. Acta. 181: 287.

7. Regoeczi, E. 1971. The clottability of iodinated fibrinogen. J. Nucl. Biol. Med. In press.

8. Ardlie, N. G., M. A. Packham, and J. F. Mustard. 1970. Adenosine diphosphate induced platelet aggregation in suspensions of washed rabbit platelets. Brit. J. Haematol. $19: 7$.

9. Mustard, J. F., D. W. Perry, N. G. Ardlie, and M. A. Packham. 1971. Preparations of suspensions of washed platelets from humans. Brit. J. Haematol. In press.

10. Ardlie, N. G., D. W. Perry, M. A. Packham, and J. F. Mustard. 1971. Influence of apyrase on stability of suspensions of washed rabbit platelets. Proc. Soc. Exp. Biol. Med. 136: 1021.

11. Mustard, J. F., B. Hegardt, H. C. Rowsell, and R. L. MacMillan. 1964. Effect of adenine nucleotides on platelet aggregation and clotting time. J. Lab. Clin. Med. $64: 548$.

12. Niewiarowski, S., and D. P. Thomas. 1969. Platelet factor 4 and adenosine diphosphate release during human platelet aggregation. Nature (London). 222: 1269.

13. Kopec, M., A. Z. Budzynski, J. Stachurska, Z. Wegrzynowicz, and E. Kowalski. 1966. Studies on the mechanism of interference by fibrinogen degradation products
(FDP) with platelet function. Role of fibrinogen in the platelet atmosphere. Thromb. Diath. Haemorrh. 15: 476.

14. Kattlove, H. E., and T. H. Spaet. 1970. The effect of chromium on platelet function in vitro. Blood. 35: 659 .

15. Bergmeyer, H. V., E. Bernt, and B. Hess. 1965. Lactic dehydrogenase. In Methods of Enzymatic Analysis. H. V. Bergmeyer, editor. Academic Press, Inc., New York. 741.

16. McFarlane, A. S. 1958. Efficient trace-labelling of proteins with iodine. Nature (London). 182: 53.

17. Stewart, G. J. 1970. A fixation-shadowing technique for electron microscopic visualization of platelets, subcellular material and fibrin. Thromb. Diath. Haemorrh. 23: 228.

18. Movat, H. Z., W. J. Weiser, M. F. Glynn, and J. F. Mustard. 1965. Platelet phagocytosis and aggregation. J. Cell Birl. 27: 531.

19. Duncan, D. B. 1955. Multiple range and multiple F-tests. Biometrics. 11: 1 .

20. Spaet, T. H., and M. B. Zucker. 1964. Mechanism of platelet plug formation and role of adenosine diphosphate. Amer. J. Physiol. 206: 1267.

21. Packham, M., C. S. P. Jenkins, R. L. Kinlough-Rathbone, and J. F. Mustard. 1971. Agents influencing platelet adhesion to surfaces and the release reaction. Circulation. 44 (Suppl. 2) : 67.

22. Niewiarowski, S., A. Poplawski, B. Lipinski, and R. Farbiszewski. 1968. The release of platelet clotting factors during aggregation and viscous metamorphosis. Exp. Biol. Med. 3: 121.

23. Cross, M. J. 1964. Effect of fibrinogen on the aggregation of platelets by adenosine diphosphate. Thromb. Diath. Haemorrh. 12: 524.

24. Brinkhous, K. M., M. S. Read, and R. G. Mason. 1965. Plasma thrombocyte agglutinating activity and fibrinogen. Synergism with adenosine diphosphate. Lab. Invest. 14: 335 .

25. McLean, J. R., R. E. Maxwell, and D. Hertler. 1965. Fibrinogen and adenosine diphosphate-induced aggregation of platelets. Nature (London). 205: 259.

26. Inceman, S., J. Caen, and J. Bernard. 1966. Aggregation, adhesion and viscous metamorphosis of platelets in congenital fibrinogen deficiencies. J. Lab. Clin. Med. 68: 21.

27. Kopec, M. Z., A. Z. Wegrzynowicz, Z. S. Budzynski, B. Latallo, Lipinski, and E. Kowalski. 1968. Interaction of fibrinogen degradation products (FDP) with platelets. Exp. Biol. Med. 3: 73.

28. Larrieu, M. J., C. Rigollot, and P. Kubisz. 1970. Platelet aggregation induced by soluble fibrin monomer complexes. Life Sci. 9(Pt. 2): 1111.

29. Solum, N. O. 1968. Aggregation of human platelets by bovine platelet fibrinogen. Scand. J. Haematol. 5: 474.

30. Marr, J., J. J. Barboriak, and S. A. Johnson. 1965. Relationship of appearance of adenosine diphosphate, fibrin formation and platelet aggregation in the hemostatic plug in vivo. Nature (London). 205: 259.

31. Rodman, N. F., and R. G. Mason. 1967. Platelet-platelet interaction: relationship to hemostatis and thrombosis. Fed. Proc. 26: 95.

32. Jørgensen, L., H. C. Rowsell, T. Hovig, and J. F. Mustard. 1967. Resolution and organization of platelet-rich mural thrombi in carotid arteries of swine. Amer. J. Pathol. 51: 681 .

Platelet Interaction with Polymerizing Fibrin 699 
33. Erikson, R. B. 1968. Platelet adhesion-morphologic observations. Exp. Biol. Med. 3: 7.

34. French, J. E. 1969. The fine structure of experimental thrombi. In Thrombosis. S. Sherry, K. Brinkhous, E. Genton, and J. M. Stengle, editors. National Academy of Science, Washington, D. C. 300.

35. Warren, B. A., and M. G. Davey. 1970. Electron microscopy of human platelet aggregates formed in vitro with and without fibrin production. Angiology. 7: 84 .

36. Sokal, G. 1960. Plaquettes sanguines et structures du caillot. Bruxelles, edition Arscia SA. 234.
37. Zucker-Franklin, D. 1969. Microfibrils of blood platelets: their relationship to microtubules and the contractile protein. J. Clin. Invest. 48: 165.

38. Baumgartner, H. R., M. B. Stemerman, and T. H. Spaet. 1971. Adhesion of blood platelets to subendothelial surface; distinct from adhesion to collagen. Experientia (Basel). 27: 283.

39. Ashford, T. P., and D. G. Frieman. 1968. Platelet aggregation at sites of minimal endothelial injury. An electron microscopic study. Amer. J. Pathol. 53: 599. 